\title{
(A falta de) Poder de definição de agenda do parlamento sobre a agenda de decisões executivas: evidências da Bélgica, França e Portugal
}

\author{
Enrico Borghetto 1 \\ Julie Sevenans ${ }^{2}$ \\ Emiliano Grossman ${ }^{3}$ \\ 1 University of Florence / Faculty of Political Sciences, Firenze - Itália \\ 2 University of Antwerp / Faculty of Political and Social Sciences, Antwerpen - Bélgica \\ 3 Sciences Po, Paris - França
}

Uma das funções das perguntas parlamentares nos espaços legislativos modernos é pressionar que os atores do executivo prestem atenção a questões específicas. Mas será que essas perguntas podem de fato influenciar as decisões do executivo? Por incrível que pareça, são poucas as pesquisas empíricas nessa área. Adotando uma perspectiva de agenda-setting, este artigo examina até que ponto a atenção dada às perguntas formuladas oralmente por parlamentares influencia os tópicos abordadas nas reuniões semanais do Conselho de Ministros em três países (Bélgica, França e Portugal). Nossas conclusões sugerem que, nos contextos analisados, o poder de definição de agenda dos parlamentos em relação ao executivo geralmente é fraco. Na Bélgica, no entanto, há evidências de que o poder executivo aborda as perguntas dos parlamentares, ressaltando-se, nesse caso, que a mídia desempenha um papel crucial ao influenciar que as questões levantadas no legislativo recebam essa atenção. Essas conclusões demonstram o domínio do poder executivo em muitas democracias ocidentais. Além disso, os resultados variados sugerem que os padrões de definição de agenda são mais complexos do que frequentemente se observa nos estudos que focam em somente um país, o que leva a crer que a pesquisa comparativa é o caminho a seguir.

Palavras-chave: parlamento; questões parlamentares; executivo; mídia; agendas políticas.

\section{(La falta de) Poder de definición de agenda del parlamento sobre la agenda de decisiones ejecutivas: evidencias de Bélgica, Francia y Portugal}

Una de las funciones de las preguntas parlamentarias en los espacios legislativos modernos es presionar para que los actores del ejecutivo presten atención a cuestiones específicas. Pero, ¿̨ueden estas preguntas influir de hecho en las decisiones del ejecutivo? Aunque parezca increíble, existen pocas investigaciones empíricas en esa área. Adoptando una perspectiva de agenda-setting, este artículo examina hasta qué punto la atención dada a las preguntas formuladas oralmente por parlamentarios influencia los temas abordados en las reuniones semanales del consejo de ministros en tres países (Bélgica, Francia y Portugal). Nuestras conclusiones sugieren que, en los contextos analizados, el poder de definición de agenda de los parlamentos en relación con el ejecutivo generalmente es débil. En Bélgica, no obstante, hay evidencia de que el Poder Ejecutivo aborda las preguntas de los parlamentarios. En este caso, vale enfatizar que los medios desempeñan un papel crucial al influir para que las cuestiones planteadas en el Legislativo reciban atención. Esas conclusiones demuestran el dominio del poder ejecutivo en muchas democracias occidentales. Además, los resultados variados sugieren que los parones de definición de agenda son más complejos de lo que frecuentemente se observa en los estudios que se enfocan solamente en un país, lo que lleva a pensar que la investigación comparativa es el camino a seguir.

Palabras clave: parlamento; cuestiones parlamentarias; ejecutivo; medios de comunicación; agendas políticas. 


\section{Parliament's (lack of) agenda-setting power over the executive decision agenda: evidence from Belgium, France and Portugal}

One of the functions of parliamentary questions in modern legislatures is to pressure executives to pay attention to specific issues. But can these questions effectively influence executive decisions? There is surprisingly little empirical research in this area. Adopting an agenda-setting perspective, this article examines the extent to which issue attention in oral parliamentary questions influences the issues addressed in the weekly meetings of the Council of Ministers in three countries (Belgium, France and Portugal). Our findings suggest that the agenda-setting power of parliaments vis-à-vis the executive is usually weak in the contexts studied here. In Belgium, we find evidence that the executive does pick up on issues debated in parliament but that the media seems to play a crucial role in focusing attention. These conclusions testify to the dominance of the executive power in many Western democracies. The findings also demonstrate that agenda-setting patterns are more complex than single-country studies often suggest, and that comparative research is the way forward.

Keywords: parliament; parliamentary questions; executive; media; policy agendas.

\section{AGRADECIMENTOS}

Este trabalho foi apoiado pela Fundação Portuguesa para a Ciência e a Tecnologia no âmbito do Contrato 422-B/2019 e do Projecto UIDB/04627/2020.

\section{INTRODUÇÃO}

Até que ponto o poder legislativo influencia a agenda do executivo? Esta é uma pergunta importante para os cientistas políticos à medida que as democracias parlamentares modernas giram em torno das relações de confiança ou desconfiança estabelecidas entre esses dois poderes. Teoricamente, os parlamentos deveriam ser capazes de atrair a atenção dos executivos para questões prementes, responsabilizando-os pelas decisões tomadas. Os vários instrumentos para isso variam de simples recomendações, ao drástico voto de desconfiança - que pode levar a queda do gabinete ministerial. Mas será que essas ferramentas parlamentares de fato influenciam as agendas executivas?

Este artigo aborda a questão concentrando-se nas perguntas sustentadas oralmente por membros do parlamento (MPs). Em muitos países, os parlamentos organizam sessões de debate em que os MPs podem elaborar perguntas e obter uma resposta oral do governo (Beyme, 2000). A maneira como as perguntas orais são usadas varia consideravelmente de acordo com os processos estabelecidos em cada país (Russo \& Wiberg, 2010). Além disso, as pesquisas sobre o funcionamento do poder legislativo apontam que, mesmo quando regulados por procedimentos semelhantes, perguntas parlamentares são usadas com diferentes finalidades (Wiberg, 1995, p. 181). Esse instrumento é adotado principalmente como ferramentas de fiscalização. Os partidos políticos, em especial os de oposição, usam as perguntas orais para controlar a conduta do governo, ou seja, para forçar os ministros a justificar suas ações ou divulgar detalhes relevantes. ${ }^{1}$ Os MPs também podem fazer perguntas localizadas e específicas, relacionadas aos interesses de seu eleitorado (ver, por exemplo, Borghetto, Santana-Pereira, \& Freire, 2020; Martin, 2011; Russo, 2011), ou com intuito de ganhar publicidade e avançar em sua carreira,

\footnotetext{
${ }^{1}$ Embora perguntas parlamentares sejam frequentemente feitas por razões puramente informativas, elas também podem ser consideradas ferramentas de controle (accountability) (Wiberg, 1995). Isso porque as respostas consideradas insatisfatórias podem levar o parlamentar a aumentar a pressão sobre o governo usando outros meios, como as interpelações e as moções de censura (ou moção de desconfiança).
} 
especialmente quando há atenção significativa da mídia (Bailer, 2011). Pesquisas recentes relacionam o aumento da atividade não legislativa à crescente importância da competição entre os diversos tópicos por espaço na agenda da Europa Ocidental, e argumentam que as perguntas parlamentares têm sido amplamente usadas para desafiar governos e pressionar os ministros a prestarem atenção a uma questão específica (Green-Pedersen, 2010).

O presente artigo foca no uso das perguntas parlamentares para influenciar a agenda do governo. Embora a literatura acadêmica tenha começado a se concentrar no potencial dessas perguntas no processo de definição de agenda, ainda faltam pesquisas em grande escala nessa área. Visamos aqui preencher essa lacuna adotando uma perspectiva de agenda-setting (Baumgartner, Breunig, \& Grossman, 2019; Green-Pedersen \& Walgrave, 2014; Jones \& Baumgartner, 2005), nos concentrando na atenção dada a determinadas questões e testando se e em que medida a preocupação dos MPs sobre um tópico afeta as decisões do executivo sobre esse mesmo tema.

Vários fatores podem afetar o processo de definição de agenda. Abordamos dois moderadores principais: se o MP que formula a pergunta é de um partido de oposição e o papel da mídia. Primeiro, os MPs da oposição e os da maioria têm diferentes incentivos para formular perguntas (Borghetto \& Chaques-Bonafont, 2019; Vliegenthart \& Walgrave, 2011). Aquelas sustentadas pela oposição geralmente atacam o executivo e tentam influenciar a agenda do Conselho de Ministros, que lhes é inacessível. Já os parlamentares da maioria têm canais diferentes à sua disposição para chamar a atenção do executivo às suas questões, como o contato direto com os ministros, por meio da relação partidária. É por isso que as perguntas sustentadas por MPs governistas raramente colocam o executivo sob pressão e, em geral, são usadas para se obter o crédito por algum resultado positivo. Esse fator é levado em consideração nas expectativas e análises apresentadas neste estudo.

Em segundo lugar, testamos até que ponto a atenção da mídia é importante para o relacionamento diário de definição de agenda entre legislativo e executivo. Espera-se que a influência das perguntas parlamentares (da maioria e da oposição) na definição da agenda do Conselho de Ministros seja maior quando o tópico também for foco da atenção da mídia. Constantemente confrontados com um fluxo extremamente complexo de problemas que exigem a atenção do executivo simultaneamente, os ministros, em um ambiente onde a mídia tem forte presença, provavelmente observam a cobertura da imprensa para avaliar se um tema deve ou não ser priorizado e discutido nas reuniões semanais (Thesen, 2014).

O presente documento está organizado da seguinte maneira: a próxima seção apresenta a literatura existente sobre a definição de agenda, enfatizando a contribuição dos estudos anteriores para a compreensão da relação entre os poderes legislativo e executivo, e oferecendo as bases de onde derivamos expectativas específicas. Em seguida, explicamos como foram rastreadas as atenções dadas pela mídia, executivo e parlamento, destacando algumas diferenças processuais entre os países analisados. Finalmente, apresentamos uma análise transversal de séries temporais e discutimos os achados, enfatizando suas implicações a partir de uma perspectiva comparativa.

\section{REFERENCIAL TEÓRICO}

Este estudo baseia-se em uma longa tradição de pesquisa, buscando entender a dinâmica da atenção dada a diferentes agendas políticas. Baseando-se no trabalho de Baumgartner e Jones nos EUA (2005, 1993), pesquisadores de vários países estudaram a 'política da atenção', na tentativa de lançar luz sobre como a atenção se move entre os vários atores políticos, sociais e da mídia (ver também Baumgartner et al., 2019; Green-Pedersen \& Walgrave, 2014). 
Embora os estudos sobre as perguntas parlamentares façam parte de um campo bem estabelecido (cf. Martin, 2011), o poder dessas perguntas no processo de definição da agenda governamental tem recebido relativamente pouca atenção. A maioria das pesquisas se concentra em explicar como as perguntas parlamentares são influenciadas por uma variedade de outros fatores. Elas têm demonstrado que as perguntas parlamentares orais ou as audiências do congresso são, por exemplo, influenciadas por manifestos partidários (Borghetto \& Russo, 2018; Otjes \& Louwerse, 2018; Vliegenthart \& Walgrave, 2011), protesto (King et al., 2007) ou, mais notavelmente, pela cobertura da mídia de massa (Edwards \& Wood, 1999; Soroka, 2002; Van Noije, Kleinnijenhuis, \& Oegema, 2008; Vliegenthart et al., 2016). Há menos estudos focando em como as perguntas orais afetam a atenção dada por outros atores, como, por exemplo, a mídia (Bartels, 1996; van Santen, Helfer, \& van Aelst, 2013), o presidente (Eshbaugh-Soha \& Peake, 2005) ou a União Europeia (Sciarini et al., 2019).

Até que ponto as perguntas parlamentares afetam as agendas executivas? Até onde sabemos, essa relação raramente tem sido abordada em pesquisas empíricas - o que é surpreendente, dado o amplo consenso de que a definição da agenda é uma das principais funções da pergunta parlamentar (Green-Pedersen, 2010; Wiberg, 1995). Bartels (1996) analisou a relação entre o Congresso e o executivo nos EUA sobre quatro questões discutidas ao longo dos anos 90 . $\mathrm{O}$ autor demonstra que, em algumas delas, o Congresso chegou a exercer alguma influência sobre o executivo. Em outro estudo, Jensen, Proksch, e Slapin (2013) observaram o Parlamento Europeu, demonstrando que perguntas parlamentares sobre violações da legislação da UE às vezes levam a Comissão a agir contra os Estados-Membros. Apesar de pequenas, essas evidências sugerem que parlamentos têm poder de exercer alguma influência sobre a definição de agenda no executivo. Abordamos o tema aqui com o objetivo de obter uma compreensão mais detalhada sobre até que ponto o parlamento cumpre com êxito sua função de definição de agenda em relação ao executivo.

A estratégia diferencial dos MPs governistas e da oposição nas perguntas parlamentares é um aspecto crucial a ser abordado. As pesquisas enfatizaram a associação entre perguntas parlamentares e os objetivos dos partidos da oposição. O instrumento da pergunta parlamentar, originalmente projetado para que o parlamento (o principal) exerça controle sobre o governo (o agente) (Saalfeld, 2000), corresponde bem ao objetivo da oposição de demonstrar a incompetência do governo. Bevan e John (2016) mostram como a oposição define o tom durante a sessão de perguntas no Reino Unido: suas perguntas forçam a liderança do partido do governo a abordar determinados temas, mais do que o governo influencia a formulação das perguntas da oposição. Na Dinamarca, as críticas estruturais da oposição à falta de atenção do governo para o meio ambiente influenciaram em certa monta as decisões do executivo (Seeberg, 2016). De um modo mais geral, um estudo longitudinal de perguntas parlamentares na Dinamarca revelou que esse expediente é uma ferramenta usada principalmente pelos MPs da oposição. Esses parlamentares indagam sobre tópicos que lhes são caros, forçando parlamentares governistas a abordá-los (Green-Pedersen \& Mortensen, 2010). Embora esses estudos não meçam diretamente o quanto a oposição influencia a atenção do governo, eles sugerem que ela, por meio das perguntas parlamentares, tem o importante papel de pressionar o executivo.

Espera-se que os partidos governistas usem o recurso da pergunta parlamentar de maneira diferente, já que atacar os ministros do próprio governo pode ameaçar a estabilidade da coalizão (De Winter \& Dumont, 2006). Isso não significa que esses MPs não façam as perguntas orais. Em muitos países eles o fazem tanto quanto os MPs da oposição. No entanto, suas motivações são diferentes. Nesse caso, pode ser mais uma questão de reivindicar crédito por resultados positivos 
ou de tentar lidar com evoluções negativas antes que a oposição tenha chance de fazê-lo (Sevenans \& Vliegenthart, 2016). ${ }^{2}$ Assumindo-se que os partidos governistas têm menos incentivos para usar as perguntas parlamentares como dispositivos de definição de agenda, a correlação entre os tópicos de atenção dos MPs governistas e os de atenção do executivo em sua reunião semanal deve ser mais fraca do que o observado no caso dos partidos da oposição (Green-Pedersen \& Mortensen, 2010).

Também levamos em consideração a mídia e veículos de comunicação de massa. Atualmente, há consenso de que a cobertura de imprensa é um dos mais importantes fatores na definição de agendas políticas (Vliegenthart et al., 2016), afetando - não apenas simbolicamente - agendas parlamentares (Walgrave \& Van Aelst, 2006) e também agendas mais substantivas, como a das decisões governamentais (ver, por exemplo, Bartels, 1996; Walgrave \& Vliegenthart, 2012). Essa questão é relevante para o nosso estudo de duas formas. Primeiro, precisamos da mídia como uma variável de controle, pois é possível que o parlamento e o executivo não estejam apenas influenciando um ao outro, mas também respondendo simultaneamente a eventos externos e à cobertura da imprensa sobre esses eventos. Segundo, consideramos a mídia um possível moderador de efeitos, já que o potencial dos parlamentares de colocar questões na agenda governamental pode depender da extensão em que eles também podem chamar a atenção da mídia para essas questões. De fato, os políticos costumam responder às questões simplesmente pelo fato de perceberem a atenção da mídia (Sevenans, 2018).

Assim, resumimos nossas expectativas em 3 hipóteses:

H1 (definição de agenda): Se os MPs fazem mais perguntas parlamentares sobre um tópico, o Conselho de Ministros prestará mais atenção a ele.

H2 (governistas versus oposição): A influência de perguntas parlamentares na definição de agenda no âmbito do Conselho de Ministros é mais forte quando essas perguntas são feitas por MPs da oposição do que quando feitas por MPs governistas.

H3 (moderação da mídia): A influência de perguntas parlamentares (feitas tanto pela oposição como por MPs governistas) na definição de agenda no âmbito do Conselho de Ministros é maior quando a mídia também está atenta ao tópico.

\section{DADOS E MÉTODOS}

A análise a seguir baseia-se em dados sobre como a atenção dispensada as políticas públicas se distribui nos parlamentos, no executivo e na mídia de três países: Bélgica, França e Portugal. Embora sejam democracias europeias 'antigas' e bem estabelecidas, as diferenças entre essas nações influenciam nas relações observadas entre seus poderes legislativo e executivo. Não vemos razão imediata para o poder de definição de agenda do parlamento sobre o executivo ser diferente entre sistemas parlamentares clássicos (como a Bélgica) e sistemas semi-presidenciais (como França e Portugal). Possivelmente o fator mais importante nesse sentido seja o formato das coalizões de governo. Nas últimas três

\footnotetext{
${ }^{2}$ Embora reconheçamos que os partidos que compõe a coalizão do governo possam usar perguntas parlamentares para acompanhar seus ministros (Höhmann \& Sieberer, 2020; Martin \& Vanberg, 2011), esse aspecto está além do escopo da presente análise. Isso não quer dizer, no entanto, que a direção de nossa hipótese seja substancialmente afetada, mesmo considerando que, em média, as perguntas da oposição possam exercer mais influência na agenda do executivo do que as perguntas formuladas por MPs governistas.
} 
décadas, a Bélgica e a França foram governadas por grupos em coalizão - frequentemente mais fragmentados na Bélgica (Deschouwer, 2012) do que na França, que geralmente é liderada por uma coalizão conservadora (liderada pelos gaullistas) ou por uma coalizão de esquerda (liderada pelos socialistas) (Elgie \& Grossman, 2016). Mesmo quando um partido detém uma maioria absoluta, como no caso da França desde 2017, o partido majoritário geralmente escolhe honrar acordos pré-eleitorais e estabelecer um governo de coalizão. Portugal pós-1974 apresentou a alternância no poder entre, principalmente, dois partidos: os socialistas (PS) e os social-democratas (PSD, geralmente em uma coalizão com os democratas cristãos do CDS-PP). Por um lado, sabemos que os sistemas de coalizão, como um meio para os parceiros acompanharem os ministros uns dos outros, normalmente produzem parlamentos e comissões mais fortes (André, Depauw, \& Martin, 2016). Por outro, parece claro supor que Conselhos de Ministros formados com a participação de um menor número de partidos (ou seja, menos atores com poder de veto), como em Portugal, sejam mais rápidos a reagir a eventos externos e adaptar sua agenda (Tsebelis, 1995). Outras diferenças possivelmente relevantes incluem, por exemplo, o tamanho da maioria (que também varia ao longo do tempo), e a composição e o tamanho do governo. Além disso, existem algumas diferenças de procedimento (conforme discutido abaixo) e os atores políticos nos três países podem assumir um papel diferente em relação à mídia, o que é relevante para a nossa terceira hipótese (Vliegenthart et al., 2016). Infelizmente, o estudo em três países não oferece a alavancagem analítica necessária para identificar as causas exatas de quaisquer distinções que possam ser (e serão) encontradas entre países, e é por isso que tratamos nossa configuração comparativa como um meio de testar a robustez dos resultados.

\subsection{Agendas parlamentar, executiva e da mídia}

O rastreamento da atenção política ao longo do tempo nas três instituições (parlamento, executivo e mídia) envolveu a codificação, por tópicos, de documentos relevantes e comparáveis dos três países, usando a metodologia e o livro de códigos desenvolvidos pelo Comparative Agendas Project (CAP, www.comparativeagendas.net). A presente análise baseia-se em conjuntos de dados coletados e codificados pelas equipes belga, francesa ${ }^{3}$ e portuguesa ${ }^{4}$ do CAP. Devido a diferenças na disponibilidade, os conjuntos de dados abrangem diferentes períodos de tempo: respectivamente de 1999 a 2008 para a Bélgica, de 1993 a 2013 para a França e de 2007 a 2015 para Portugal. Contamos com três conjuntos de dados distintos, codificados em 21 tópicos principais (a lista de tópicos podem ser encontrados na Figura 1$)^{5}$ :

- Artigos de capa de um grande jornal nacional, com intuito de reconstruir a agenda da mídia de massa (19.010 artigos do De Standaard; 28.055 artigos do Le Monde; e 21.769 artigos do Público);

\footnotetext{
${ }^{3} \mathrm{O}$ conjunto original de dados sobre as perguntas parlamentares na França foram coletadas de Navarro e Brouard (2014). O trabalho de construção desse banco de dados foi financiado com recursos do projeto ANR-08-Gouv-055.

${ }^{4}$ O Projeto em Portugal recebeu o apoio da Fundação para a Ciência e a Tecnologia com financiamento de dois projetos pesquisa: "Public preferences and Policy decision-making: a comparative analysis" (PTDC/IVC-CPO/3921/2012) e "Portuguese Parliament: Agenda-setting and Law-making" (IF/00382/2014).

${ }^{5}$ Os procedimentos de codificação e os testes de confiabilidade são apresentados em detalhes nos capítulos sobre cada país, em Baumgartner et al. (2019).
} 
- Perguntas parlamentares feitas oralmente no plenário, observando por elas a agenda parlamentar (4.257 mondelinge vragen; 6.405 questions orales; e 1.638 perguntas no debate quinzenal com o primeiro-ministro);

- As decisões das reuniões do Conselho de Ministros, relatada no resumo semanal para a imprensa, observando por esses documentos a agenda executiva (7.139 decisões relatadas no resumo geral semanal para a imprensa, disponibilizado pelo Conselho (Feiten); 2.646 decisões apresentadas nos Communiqués du Conseil des ministres; e 8.257 decisões nos Comunicados do Conselho de Ministros).

A escolha pelas perguntas orais e não por manifestações escritas foi feita pelo interesse nas estratégias usadas pelos partidos quando em competição pelos seus tópicos. As perguntas escritas geralmente dão aos MPs alguma margem de manobra para avançar com agendas individualizadas. Ainda, não há um número limite de perguntas e essas manifestações não são normalmente cobertas pela grande imprensa, tornando-as menos adequadas para o escopo deste projeto. As perguntas parlamentares orais em sessão plenária estão sujeitas a restrições de tempo (algumas horas a cada semana ou a cada duas semanas) e são mais importantes do ponto de vista político, uma vez que implicam a presença de ministros no parlamento e uma maior cobertura da mídia. O estudo não assume que todas as perguntas orais sejam destinadas a atrair a atenção do executivo, pois algumas delas são meramente solicitações de informação. Mesmo que somente algumas perguntas parlamentares consigam atrair a atenção do executivo, esse fenômeno será visível em nossa análise.

Os documentos codificados nos três países são amplamente comparáveis, mas algumas diferenças processuais entre os casos devem ser apontadas. No que diz respeito às perguntas parlamentares orais, os parlamentares belgas podem fazer perguntas ao governo (primeiro-ministro e ministros) pelo menos uma vez por semana (Norma 124 do Regimento), e devem notificar o assunto da pergunta com um dia de antecedência. Na França (art. 133 do regulamento interno), as "perguntas ao governo" (primeiro-ministro e ministros) também são realizadas semanalmente (art. 48 da Constituição de 1958) e não precisam ser enviadas com antecedência. O regulamento interno prevê sessões regulares de perguntas orais (com o primeiro-ministro) a cada duas semanas. Diferente do que ocorre na Bélgica e na França, algumas das perguntas em Portugal não são levantadas por iniciativa dos MPs. As perguntas são feitas após um discurso inicial do primeiro-ministro, e dizem respeito aos temas tratados no discurso. Depois dessa etapa, segue-se como na Bélgica e na França, com os parlamentares fazendo suas próprias perguntas, seguidas pelas respostas improvisadas do primeiro-ministro. Para concluir, há diferenças no tempo das sessões plenárias (semanal versus duas semanas), no ator para o qual a pergunta é endereçada (se a todos os ministros ou se apenas o primeiro-ministro) e na condução das perguntas (se submetidas antecipadamente versus no local versus parcialmente reativas) que levamos em consideração ao analisar os dados e interpretar os resultados.

Os comunicados de imprensa dos Conselhos de Ministros são mais comparáveis: eles são apresentados semanalmente e relatam todas as decisões comunicadas à mídia pelo primeiro-ministro e os demais membros do gabinete no final de sua reunião (Borghetto \& Belchior, 2019). Como as atas das reuniões não são disponibilizadas, esses são os melhores documentos para identificar os tópicos que prendem a atenção do executivo. Os relatórios diferem em tamanho e formato nos três países, mas têm o mesmo status e incluem pelo menos todas as propostas de lei, decretos ministeriais, nomeações e regulamentos administrativos, bem como decisões de política externa. 


\subsection{Variáveis dependentes e independentes}

Para calcular a atenção dada a um tópico $i$ na semana $t$, decidimos usar a quantidade de perguntas, de decisões executivas e de artigos de jornal que se enquadram em cada um dos 21 principais tópicos da semana. Para testar a H2, as perguntas parlamentares orais foram divididas de acordo com a posição do partido do MP que a elabora (se governista ou de oposição) e foi calculada a média da atenção prestada para os partidos que se encontram em cada uma das duas posições.

A Tabela 1 mostra a quantidade total e a proporção de perguntas nos dois países. Mostra que as perguntas sustentadas pelos governistas são uma minoria em Portugal (16\% do total), mas constituem quase metade das perguntas na Bélgica (42\%) e uma proporção ainda maior na França (62\%). Esse resultado reflete tanto as regras dos parlamentos (por exemplo, na Bélgica, cada parte tem um número máximo fixo de perguntas que pode ser feito toda semana), como o formato da coalizão governamental (as perguntas da maioria fazem pouco sentido nos governos de partido único de Portugal, por exemplo).

\section{TABELA 1 DISTRIBUIÇÃO DOS TÓPICOS ENTRE GOVERNISTAS E OPOSIÇÃO}

\begin{tabular}{|c|c|c|c|c|}
\hline País & Anos & Governistas & Oposição & Total \\
\hline Portugal & 2007-2015 & 138 (17\%) & 696 (83\%) & 834 \\
\hline Bélgica & 1999-2008 & 1387 (42\%) & 1897 (58\%) & 3284 \\
\hline França & 1993-2013 & 3776 (62\%) & 2322 (38\%) & 6098 \\
\hline
\end{tabular}

Fonte: Elaborada pelos autores.

A Figura 1 (consulte o Anexo A para as tabelas que mostram todos os valores usados nas três figuras, mais as porcentagens da mídia) dá uma visão geral da distribuição de atenção nas agendas parlamentares e executivas nos três países em estudo. A análise das perguntas parlamentares indica que tanto governistas como a oposição na Bélgica e na França dedicam mais atenção ao mesmo grupo de questões: justiça e criminalidade, operações do Estado, transportes e saúde. Não existe uma sobreposição tão clara em Portugal, mas questões de macroeconomia, política social e as operações do Estado aparecem consistentemente entre as quatro primeiras. Esses resultados nos alertam para dois aspectos relevantes do questionamento oral. Primeiro, há uma permanente alternância entre governistas e oposição, lidando com eventos atuais - o que significa que os dois grupos costumam falar sobre os mesmos problemas. Segundo, o momento de perguntas em Portugal tende a lidar com questões mais gerais (por exemplo, sobre o estado da economia, macroeconomia ou funcionamento do aparato administrativo, operações do Estado) do que o observado nos outros países analisados. Isso se deve ao fato de que apenas o primeiro-ministro participa do momento de perguntas em Portugal, uma circunstância que limita o grau de tecnicidade das perguntas (por exemplo, é provável que, se perguntado sobre o estado do serviço ferroviário, o primeiro-ministro passe a questão adiante ao 
ministro do transporte). No que diz respeito à agenda do Conselho de Ministros, não houve surpresa em observar que o tópico "operações do Estado" é proeminente em todos os países. Os tópicos restantes têm uma classificação diferente nos três casos, embora a atenção seja bastante distribuída entre eles.

\section{FIGURA 1 MÉDIA DA ATENÇÃO SEMANAL AOS TÓPICOS, POR TÓPICO NAS PERGUNTAS PARLAMENTARES E NA AGENDA DO EXECUTIVO}
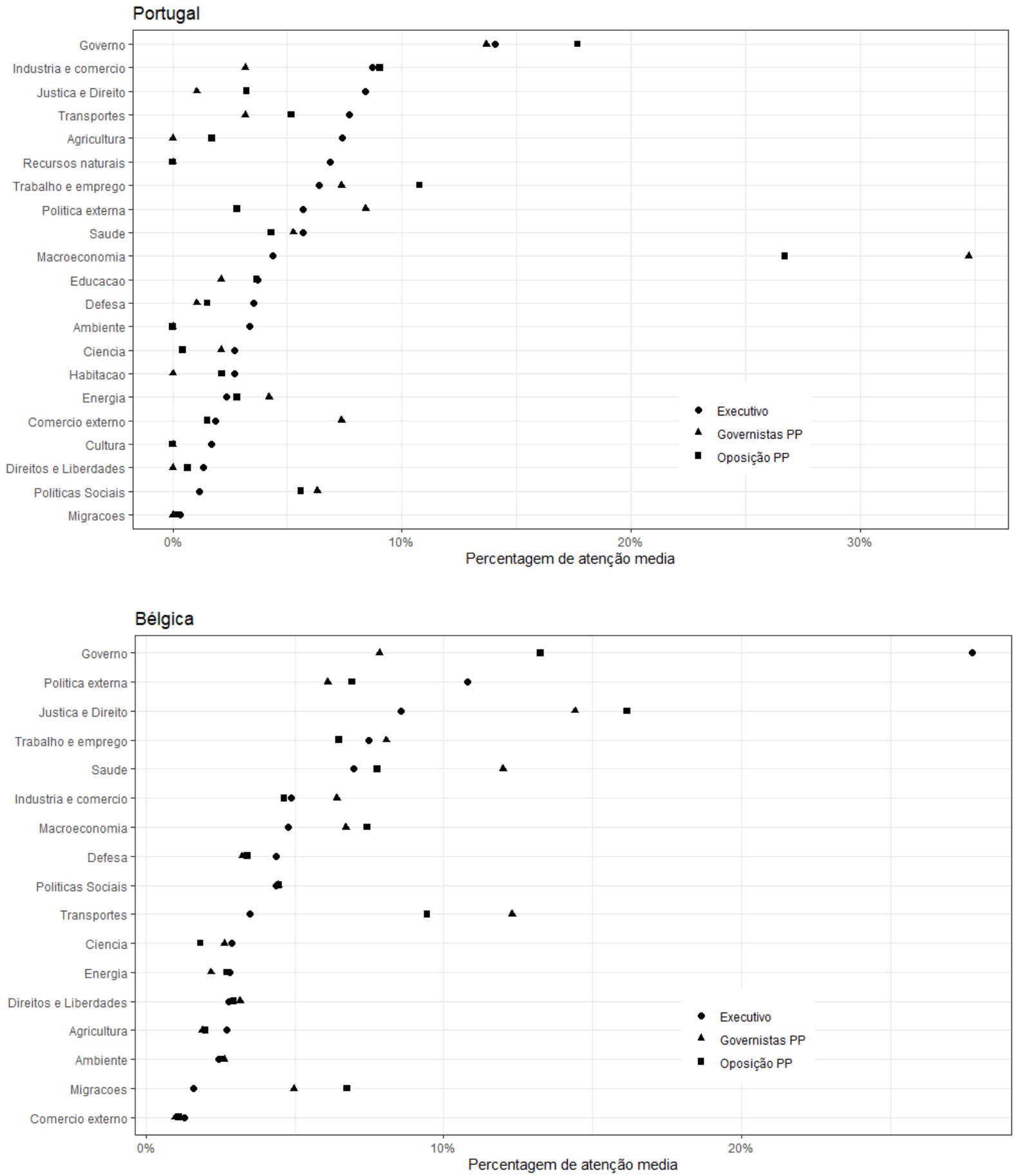

Revista de Administração PÚblica ｜ Rio de Janeiro 54(6):1588-1612, nov. - dez. 2020 


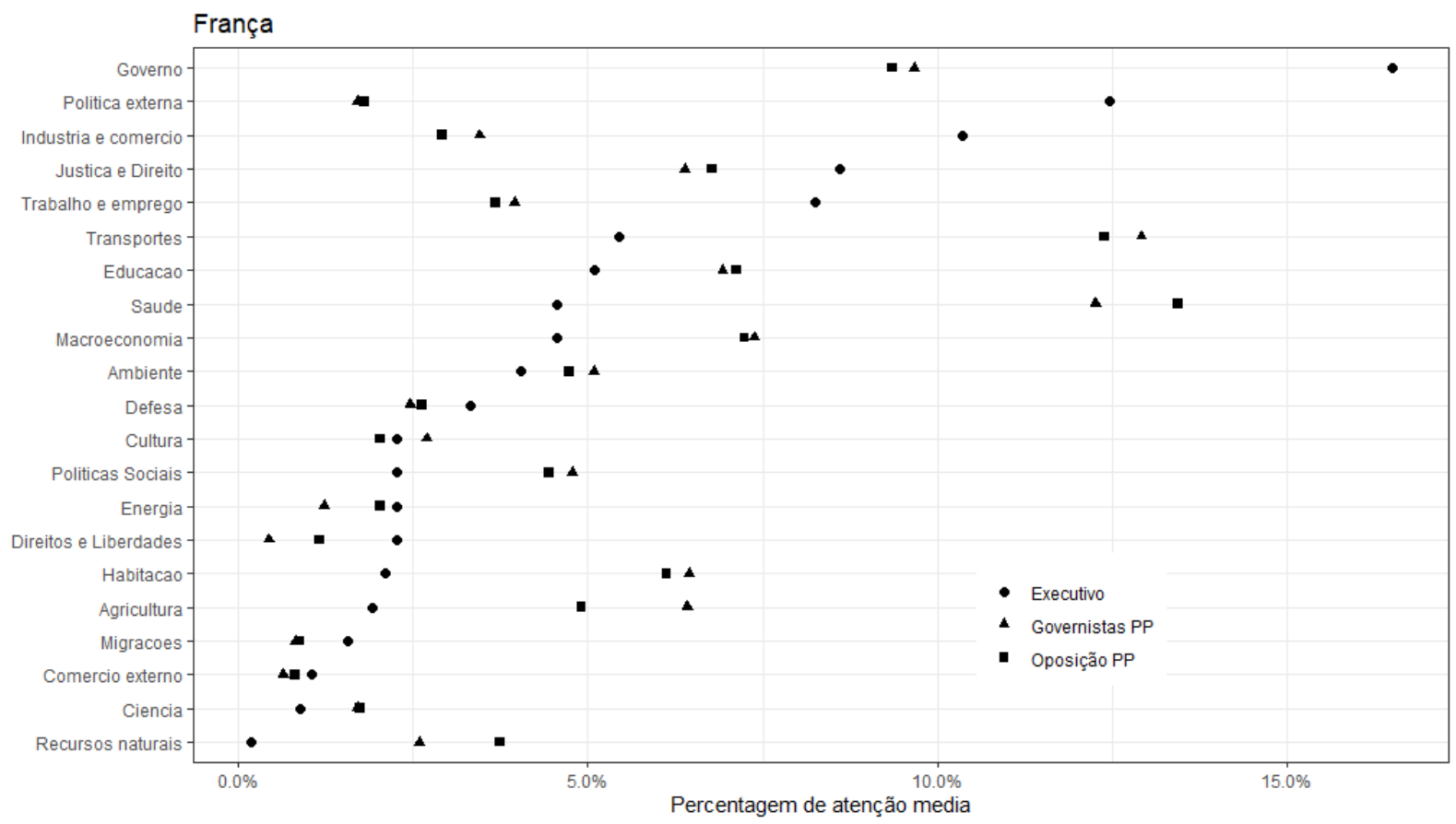

Fonte: Elaborada pelos autores.

Antes de passarmos a testar as hipóteses propostas, oferecemos mais algumas informações sobre os dados, elaborando brevemente a diversidade de tópicos abordados em uma semana específica. A pesquisa de definição de agenda nos ensinou que as agendas são caracterizadas por diferentes níveis de atrito: limites institucionais e cognitivos restringirão a capacidade de resposta das agendas a estímulos externos. $\mathrm{O}$ atrito cria um gargalo de atenção, limitando o número de problemas tratados em um determinado momento (Jones \& Baumgartner, 2005). Esses limites podem ser mais ou menos importantes, dependendo da agenda. Embora algumas delas sejam bastante "abertas" e, portanto, altamente responsivas às mudanças que ocorrem no mundo real - e com oportunidades para abordar vários tópicos simultaneamente -, outras podem ser muito mais restritas. Para o objetivo deste estudo, podemos esperar que as agendas da mídia sejam caracterizadas por níveis mais baixos de atrito do que as agendas políticas.

A agenda política, particularmente a do governo, pode ser entendida como um enorme dispositivo de filtragem. Muitas conquistas importantes podem ser alcançadas por meio de um processamento paralelo, mas estudos mostram que as autoridades de governo estão sujeitas a uma racionalidade limitada, que as impede de reagir de acordo com as demandas colocadas por novas circunstâncias (Jones, Larsen-Price, \& Wilkerson, 2009, p. 282). 
Belgium
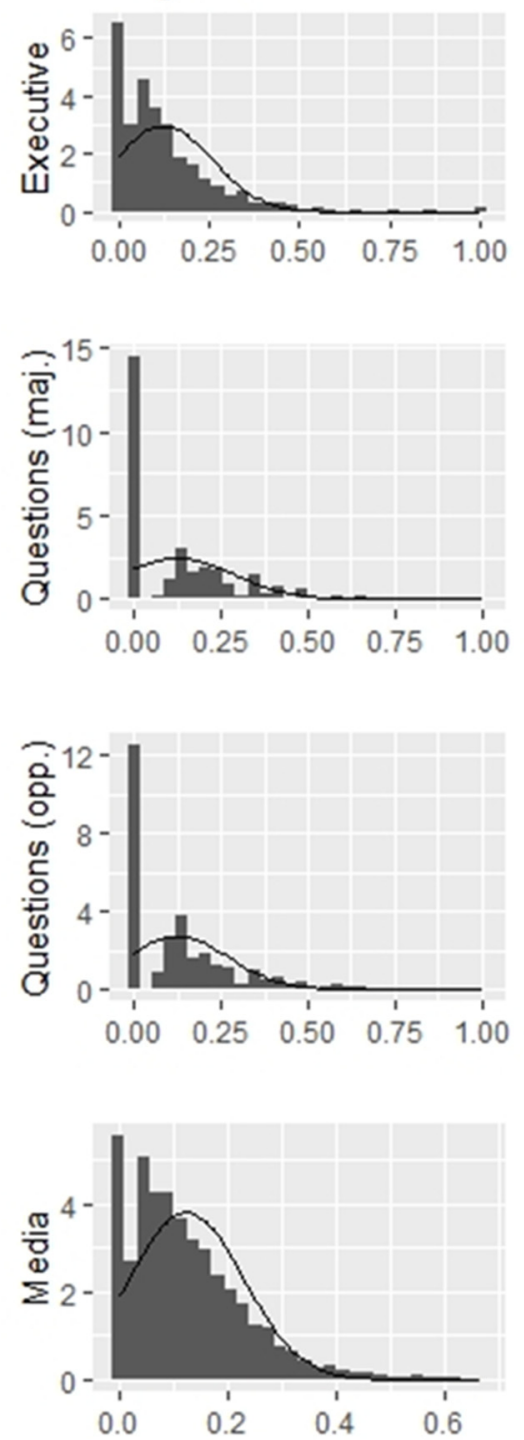

France
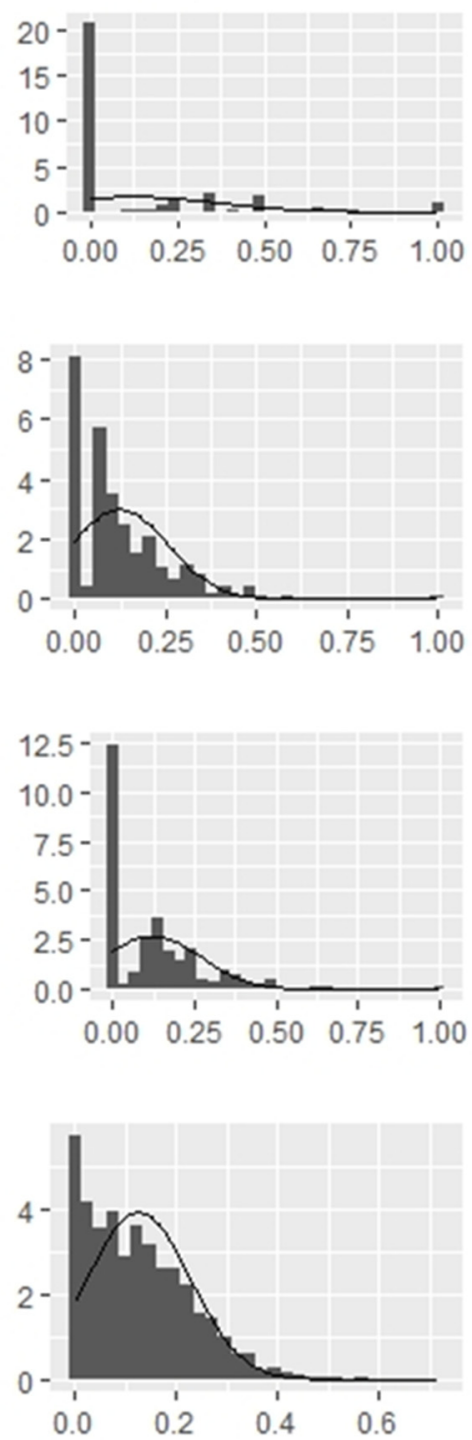

Portugal
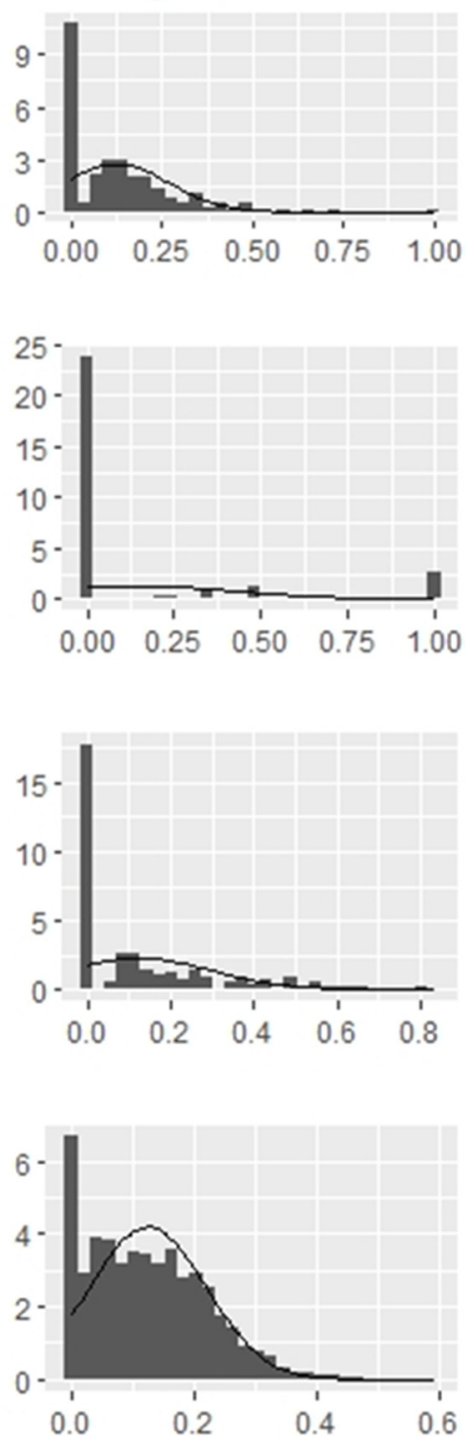

Fonte: Elaborada pelos autores.

A Figura 2 apresenta a distribuição relativa (gráficos de densidade) de atenção para cada agenda. Para ser coerente com o restante da análise abaixo, dividimos as perguntas parlamentares em perguntas de MPs governistas e da oposição. Os gráficos mostram a parcela relativa de atenção por tópico por semana. Para fins de comparação com a distribuição real, também plotamos a distribuição normal (linhas pretas): na medida em que as mudanças no mundo real são aleatórias, uma distribuição sem atrito deve ser normal. Quanto mais distorcida a distribuição, mais a agenda deve apresentar sinais de atrito. 
Como esperado, a agenda da mídia apresenta a distribuição mais "normal” nos três países. Sem surpresa, os jornais são especialistas em processamento paralelo e tentam acompanhar as mudanças no mundo real. Embora isso não signifique que as notícias não estejam sujeitas a atritos (Boydstun, 2013), certamente há menos atrito nesse caso do que nas questões parlamentares ou na agenda executiva.

A ordem das duas outras agendas difere nos três países. Embora isso se deva, em parte, ao menor número de observações nas outras agendas, essas diferenças ainda são interessantes. Na França, há um número muito maior de tópicos na agenda parlamentar que não recebem atenção semanal e poucos temas que recebem níveis de atenção excepcionalmente altos. A agenda executiva apresenta uma distribuição fortemente "leptocúrtica" com um pico zero muito alto e caudas longas (Baumgartner \& Jones, 2005). Na Bélgica e em Portugal, diferentemente, as perguntas parlamentares apresentam distribuições mais distorcidas em comparação com as agendas executivas.

\subsection{Modelo}

Para o objetivo das análises multivariadas a seguir e em consonância com nossas três hipóteses, analisamos o efeito das agendas parlamentares governistas (Majority $P Q(\operatorname{lag})$ ) e da oposição (Opposition $P Q($ lag)) nas agendas executivas (Executive) nos três países, controlando e interagindo com a agenda da mídia (Media(lag)). Ao incluir todas as três variáveis independentes simultaneamente nos modelos, controlamos muitas das variáveis de confusão que podem afetar as agendas de ambas os grupos parlamentares. Como o número de documentos varia ao longo das semanas, medimos a atenção aos tópicos como a proporção de documentos dedicados a um tema específico em relação ao total daquela semana. Usamos um entendimento superficial da causalidade como "precedência temporal". Em outras palavras, quando testamos o "efeito" da agenda da oposição na agenda executiva, nos referimos, ceteris paribus, à correlação entre o percentual de atenção (em todos os tópicos) nas questões parlamentares da oposição na semana $t_{-1}$ e no executivo na semana $t .{ }^{6}$ As análises a seguir baseiam-se em modelos de séries temporais com efeitos fixos no nível dos tópicos. ${ }^{7}$ Os conjuntos de dados foram montados em forma de painel de dados, em que os painéis são os 21 principais tópicos e o tempo é a semana em que o Conselho de Ministros se reuniu. Para explicar a autocorrelação na variável dependente, também incluímos o percentual de atenção do executivo ao tópico na semana anterior (Executive(lag)). Nossas especificações de modelo são resumidas pelas seguintes equações:

Executive $=$ Media $($ lag $)+$ Majority $P Q($ lag $)+$ Opposition $P Q($ lag $)+$ Executive $($ lag $)+$ tópicos principais Executive $=$ Media $(\mathrm{lag})+$ Media $($ lag $){ }^{\star}$ Majority PQ(lag) + Majority PQ(lag) + Opposition PQ(lag) + Executive(lag) + tópicos principais

Executive $=$ Media $($ lag $)+$ Media $(\text { lag })^{\star}$ Opposition $\mathrm{PQ}(\mathrm{lag})+$ Opposition $\mathrm{PQ}(\mathrm{lag})+$ Majority $\mathrm{PQ}(\mathrm{lag})$ + Executive(lag) + tópicos principais

\footnotetext{
${ }^{6}$ Como costuma ocorrer nas pesquisas de definição de agenda (ver, por exemplo, Vliegenthart \& Walgrave, 2011) para evitar zeros excessivos, semanas sem decisões executivas (por exemplo, durante o recesso ministerial) são deixadas de fora do conjunto de dados, resultando em um 'ano reduzido'. Se não houve debate no momento de perguntas em $t_{-I}$, decidimos usar os dados do debate mais recente até um mês distante da data da reunião executiva.

${ }^{7}$ Os testes de Hausman recomendam o uso de efeitos fixos sobre tópicos aleatórias.
} 


\section{RESULTADOS E DISCUSSÃO}

As Tabelas 2 e 3 apresentam os resultados para os modelos empilhados e específicos, respectivamente, para cada país, testando as três hipóteses em relação a influência dos MPs governistas e da oposição na definição da agenda de decisões executivas. Enquanto o modelo empilhado, que inclui dummies dos países, serve para testar nossas hipóteses em geral, os modelos separados testam se os resultados são robustos entre os países. O Modelo $1 \mathrm{em}$ cada tabela relata os resultados do modelo contendo apenas efeitos principais, que permitem testar H1 (definição da agenda) e H2 (governistas versus oposição), enquanto os modelos 2 e 3 introduzem efeitos de interação entre mídia e, respectivamente, perguntas orais sustentadas pelos governistas e pela oposição (sempre a versão defasada) para testar o H3 (moderação da mídia). Antes de discutir os resultados, observamos que, em geral, a atenção do executivo depende fortemente do caminho, conforme indicado pelos coeficientes positivos e estatisticamente significantes para suas defasagens correspondentes.

A H1, propondo que existe influência das perguntas parlamentares na definição da agenda executiva e a $\mathrm{H} 2$, que foca na influência das perguntas sustentadas pelos MPs da oposição em comparação com as sustentadas por MPs de partidos governistas), não foram validadas. Os coeficientes de Majority PQ (lag) e de Opposition PQ (lag) na Tabela 2, modelo 1, não são estatisticamente significantes nos níveis convencionais. Essa constatação revela que simplesmente abordar o gabinete no plenário, a partir das perguntas parlamentares orais, não tem efeito direto na reação do executivo, ou seja, as perguntas dos governistas e da oposição não exercem os efeitos esperados para definir a agenda executiva. O resultado é válido para os três países (Tabela 3) e é, em grande parte, confirmado se executarmos o modelo usando diferentes especificações de defasagem $\left(t_{-2}\right.$ e $t_{-3}$, ver anexos $\mathrm{B}$ e C $)$. As perguntas parlamentares parecem ser um instrumento surpreendentemente malsucedido para atrair a atenção do Conselho de Ministros para os tópicos de interesse. Obviamente, isso não significa que esse instrumento não possa exercer nenhuma pressão sobre o governo para que atente a determinados assuntos. Por exemplo, os governos que se sentem impelidos a responder a ataques parlamentares podem fazê-lo por meio de declarações gerais (por exemplo, na imprensa), em vez de rapidamente tomar decisões executivas. De fato, a agenda do gabinete geralmente é estabelecida com bastante antecedência e uma parte justa de seu conteúdo é dedicada a decisões administrativas. Portanto, nem sempre o gabinete ministerial será receptivo à introdução de novos tópicos por pressão parlamentar. Como alternativa, o executivo pode reagir mais lentamente e o tempo entre uma pergunta e uma resposta pode variar, dificultando a descoberta dessa dinâmica de influência por meio do tipo de análise defasada proposta aqui. ${ }^{8}$ Dito isso, continua a ser notável que, apesar das perguntas parlamentares constituírem um método convencional e bem estabelecido para detectar influências na definição de agendas, parece não haver absolutamente nenhuma resposta imediata do Conselho de Ministros ao parlamento.

Como exceção, descobrimos que tópicos levantados em perguntas parlamentares têm chance de aparecer na agenda do Conselho Ministerial da Bélgica nas semanas subsequentes a sessão em plenário, mas somente quando a mídia também decide prestar atenção ao tópico específico (confirmando a H3 para o caso belga). Essa constatação vale para as perguntas formuladas tanto pelos governistas

\footnotetext{
${ }^{8}$ Como um teste de robustez, os anexos B e C apresentam nossos modelos nas Tabelas 2 e 3, mas computados usando uma especificação de defasagem de tempo diferente, respectivamente $t_{-2}$ e $t_{-3}$. Porém, para alguns efeitos específicos de cada país (o impacto do Majority $P Q\left(\operatorname{lag} t_{-2}\right.$ ) é positivo e significativo para Portugal e o impacto do Majority PQ (lag $t_{-3}$ ) é negativo e significativo para a França), os resultados restantes são amplamente comparáveis e confirmam que o poder de definição de agenda do parlamento é notavelmente fraco.
} 
quanto pela oposição, ou seja, as perguntas parlamentares, quando combinadas com o interesse da mídia, se tornam atraentes do ponto de vista da agenda executiva, ao menos na Bélgica. Por fim, os debates no momento de perguntas cobrem principalmente eventos atuais, mas nem todos os eventos chegam à primeira página dos principais jornais. Quando atingem a mídia de massa e são expostos em debates parlamentares televisionados nacionalmente, a pressão aumenta e é difícil para o governo permanecer em silêncio.

Nos outros dois países, no entanto, essa moderação da mídia não ocorre e não afeta a agenda do Conselho Ministerial, mesmo quando a mídia e o parlamento se concentram em conjunto em algum tópico (rejeitando H3 para França e Portugal). De fato, o coeficiente positivo e significante do efeito de interação na análise empilhada (modelo 3, Tabela 2) parece ser impulsionado pelos dados belgas. $\mathrm{Na}$ França, os resultados são insignificantes. Em Portugal, contrariamente às expectativas, o efeito da interação entre o questionamento da oposição e a atenção da mídia é ainda negativo e significante.

\section{TABELA 2 DETERMINANTES DA ATENÇÃO DADA AOS TÓPICOS NA AGENDA DO EXECUTIVO (EMPILHADO, EFEITOS FIXOS SOBRE PAÍS E TÓPICO PRINCIPAL)}

\begin{tabular}{|c|c|c|c|}
\hline & $\begin{array}{c}\text { Modelo } 1 \\
\text { Efeitos principais }\end{array}$ & $\begin{array}{l}\text { Modelo } 2 \\
\text { Interação }\end{array}$ & $\begin{array}{l}\text { Modelo } 3 \\
\text { Interação }\end{array}$ \\
\hline Mídia(lag) & $\begin{array}{l}0,035 \\
(0,027)\end{array}$ & $\begin{array}{l}0,032 \\
(0,029)\end{array}$ & $\begin{array}{c}0,010 \\
(0,029)\end{array}$ \\
\hline Executivo(lag) & $\begin{array}{l}0,058^{\cdots+*} \\
(0,011)\end{array}$ & $\begin{array}{l}0,058^{\cdots} \\
(0,011)\end{array}$ & $\begin{array}{l}0,057^{+\cdots *} \\
(0,011)\end{array}$ \\
\hline Governistas PP(lag) & $\begin{array}{l}-0,012 \\
(0,013)\end{array}$ & $\begin{array}{l}-0,015 \\
(0,017)\end{array}$ & $\begin{array}{l}-0,012 \\
(0,013)\end{array}$ \\
\hline Oposição PP(lag) & $\begin{array}{c}0,004 \\
(0,015)\end{array}$ & $\begin{array}{c}0,004 \\
(0,015)\end{array}$ & $\begin{array}{l}-0,022 \\
(0,020)\end{array}$ \\
\hline França & $\begin{array}{l}0,006 \\
(0,003)\end{array}$ & $\begin{array}{l}0,006 \\
(0,003)\end{array}$ & $\begin{array}{l}0,007^{*} \\
(0,003)\end{array}$ \\
\hline Portugal & $\begin{array}{c}0,006 \\
(0,004)\end{array}$ & $\begin{array}{c}0,006 \\
(0,004)\end{array}$ & $\begin{array}{l}0,006 \\
(0,004)\end{array}$ \\
\hline $\begin{array}{l}\text { Mídia(lag)*Governistas } \\
\text { PP(lag) }\end{array}$ & & $\begin{array}{c}0,034 \\
(0,150)\end{array}$ & \\
\hline $\begin{array}{l}\text { Mídia(lag)*Oposição } \\
\text { PP(lag) }\end{array}$ & & & $\begin{array}{l}0,332 \\
(0,166)\end{array}$ \\
\hline Observações & 9203 & 9203 & 9203 \\
\hline
\end{tabular}

Nota: Coeficientes dos efeitos fixos do tópico principal não apresentados na tabela. $\mathrm{p}<0,05 \quad{ }^{* *} \mathrm{p}<0,01 \quad{ }^{* * *} \mathrm{p}<0,001$ Fonte: Elaborada pelos autores. 


\section{TABELA 3}

\section{DETERMINANTES DA ATENÇÃO DADA AOS TÓPICOS NA AGENDA DO EXECUTIVO (PAíSES EM SEPARADO, EFEITOS FIXOS SOBRE PAÍS E TÓPICO PRINCIPAL)}

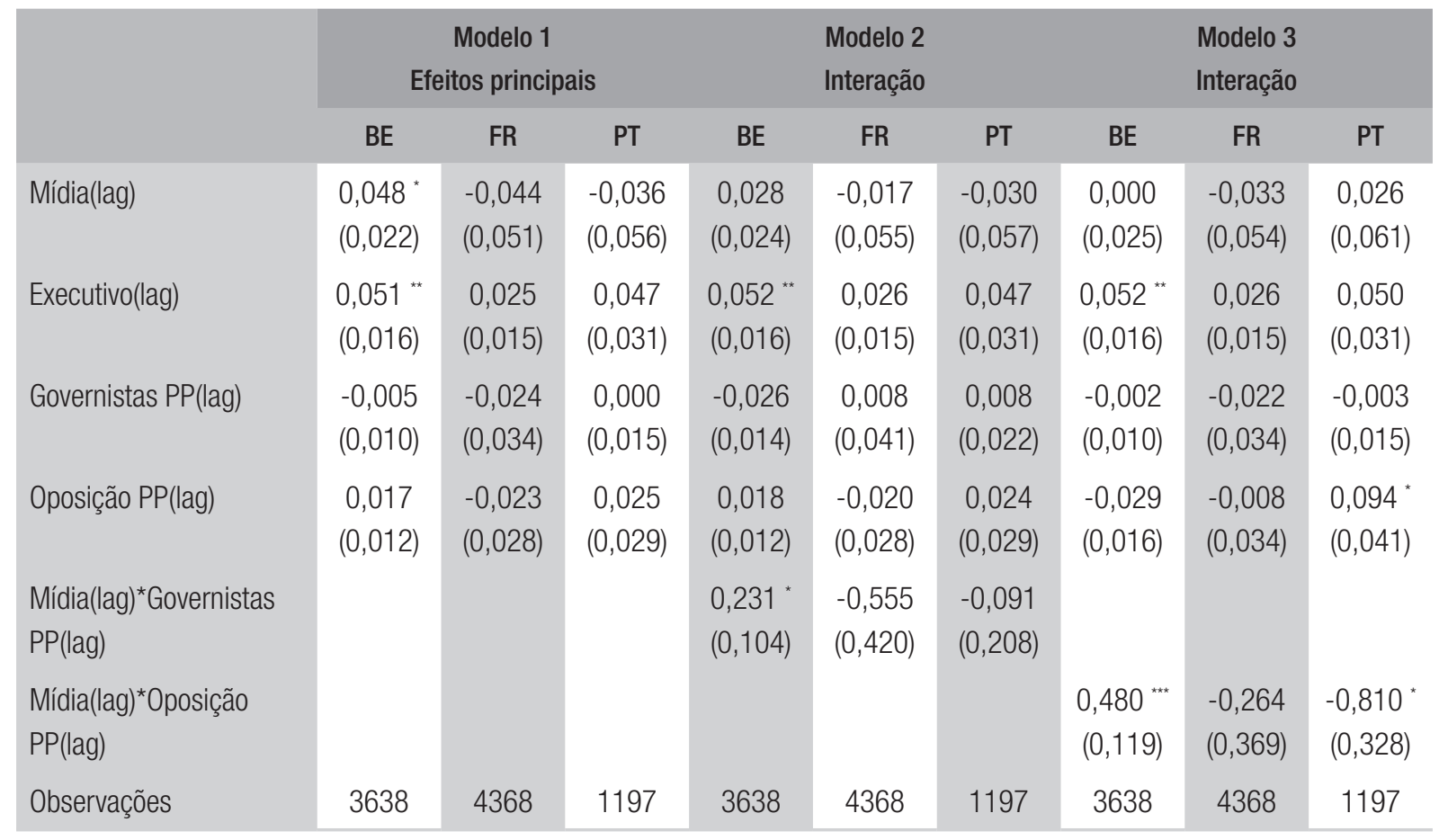

Nota: Coeficientes dos efeitos fixos do tópico principal não apresentados na tabela. $\mathrm{p}<0,05{ }^{\star *} \mathrm{p}<0,01 \quad{ }^{* * *} \mathrm{p}<0,001$ Fonte: Elaborada pelos autores.

Sobre as razões para esses resultados divergentes, cabe apenas especulação. A diferença entre Bélgica e França, acreditamos, tem a ver com a sensibilidade dos atores políticos à mídia de massa. Uma comparação de sete países mostrou que os parlamentares na França são uma exceção notável na Europa Ocidental, pois não respondem muito à mídia ao determinar suas prioridades de assuntos, e suas iniciativas raramente chegam à imprensa (Vliegenthart et al., 2016). Além disso, sabemos que a mídia e a atenção parlamentar tendem a se reforçar quando concentram sua atenção em determinadas questões. Portanto, os MPs são fracos em termos de capacidade de definição de agenda quando sozinhos, tanto na França quanto na Bélgica; no entanto, no caso belga, quando aliados à mídia, os MPs ficam em condição de pressionar o governo. Esse mecanismo de amplificação raramente ocorre na França.

Os resultados em Portugal são mais difíceis de explicar. O coeficiente negativo e significante do efeito de interação sugere que, quando os parlamentares da oposição e a mídia se concentram em um assunto, o executivo presta uma atenção significativamente menor ao tópico em questão. Uma explicação pode estar na natureza mais reativa das perguntas orais em Portugal (em comparação com a Bélgica ou a França). Como explicamos acima, parte do momento de perguntas é dedicada às perguntas feitas em reação ao discurso de abertura do primeiro-ministro. Elas permitem que os parlamentares responsabilizem o governo pelo que ele fez (controle ex post), em vez de servir para atrair a atenção do executivo para questões específicas (controle ex ante por meio da definição de agenda). Se é precisamente esse tipo de pergunta que é frequentemente abordada pela mídia, parece lógico que 
o executivo responda menos: o debate executivo sobre os tópicos subjacentes a essas perguntas acaba de ser encerrado. Como alternativa, pode ser que a natureza mais geral das perguntas em Portugal (em comparação com a natureza específica das questões francesas e belgas) - que decorre do fato de que apenas o primeiro-ministro esteja presente durante o momento de perguntas - as torne menos favoráveis a uma resposta imediata do executivo.

\section{CONCLUSÃO}

Este estudo procurou esclarecer a relação relevante, mas até agora relativamente pouco explorada, entre os instrumentos de controle parlamentar e a conduta do governo, concentrando-se nas perguntas parlamentares como elementos de definição de agenda. A análise teve como objetivo testar até que ponto as perguntas parlamentares são bem-sucedidas em atrair a atenção ministerial para alguns tópicos, e em que circunstâncias. Fizemos isso por meio de um projeto de pesquisa de grande porte que estudou a influência da atenção dada a certos temas quando da formulação de perguntas parlamentares orais na definição da agenda dos Conselhos de Ministros em três países, Bélgica, França e Portugal.

Nossas conclusões indicam que a eficácia das perguntas parlamentares orais no plenário como ferramenta que influencia a definição de agenda executiva é fraca nos três países. Não há evidências de que a atenção dada a tópicos no legislativo seja transmitida diretamente ao governo. A explicação que consideramos mais convincente para esse fenômeno é que nossa análise se limita a reações do executivo no curto prazo e, a menos que as circunstâncias exijam um decisão executiva imediata (por exemplo, em casos de desastre natural ou crise internacional), os gabinetes provavelmente preferem primeiro divulgar uma declaração e depois escolher o melhor momento para decidir sobre o tema. Essa constatação é confirmada nos três países estudados e a consideramos como relevante: à medida que o executivo adia sua reação, a atenção provavelmente desaparece, de modo que fica mais fácil para os ministros se absterem de enfrentar os problemas. $\mathrm{O}$ fato de o parlamento não poder forçar uma decisão executiva mais rápida é, portanto, outra indicação do forte domínio do poder executivo em muitas democracias ocidentais.

A situação pode ser diferente nos casos em que há uma presença simultânea de atenção da mídia nos mesmos tópicos. Na Bélgica, a combinação de mídia e atenção parlamentar sobre algum tópico pode desencadear uma tomada de decisões executivas. Esse resultado remete diretamente a pesquisas anteriores sobre o vínculo estreito entre perguntas parlamentares e meios de comunicação de massa (Vliegenthart et al., 2016). A observação de que "para o governo, não existe algo equivalente ao direito de ficar calado" (Norton, 1993, p. 112, tradução nossa), é especialmente verdadeira quando o assunto é digno de notícia e politicamente relevante. Por várias possíveis razões, que não podemos destrinchar no presente artigo, a mídia não desempenha um papel tão amplificador de definição de agenda na França ou em Portugal.

No geral, a análise feita aqui é apenas um primeiro passo na busca de uma maior compreensão da função das perguntas parlamentares no processo de definição de agenda. Os resultados encontrados sugerem (sem ainda apresentar uma teoria ou testes) que os níveis de transmissão da agenda parlamentar à agenda executiva podem ser estruturados e delimitados por formas institucionais ou históricas de atrito, específicas para cada agenda e cada país. Existe uma literatura substancial com foco no desenho institucional para o comportamento legislativo (André et al., 2016; Wiberg, 1995). As diferenças na constelação governamental (por exemplo, governos unipartidários versus 
RAP | (A falta de) Poder de definição de agenda do parlamento sobre a agenda de decisões executivas: evidências da Bélgica, França e Portugal

multipartidários), a força do parlamento e as especificidades do sistema de mídia afetam as estruturas de incentivo enfrentadas pelos atores políticos operando nessas instituições, e é provável que isso tenha implicações no grau em que o parlamento exercerá pressão de definição de agenda sobre o executivo.

O pequeno número de países observados aqui nos impede de explorar essas diferenças institucionais, o que representa uma limitação óbvia do estudo. Neste artigo, partimos da expectativa genérica de que, independentemente das diferenças institucionais, os parlamentos devem ter alguma influência na definição de agenda sobre os governos. No entanto, o que descobrimos é que essa influência, quando existe, é fortemente relacionada a um contexto específico, revelando que se deve ter cautela ao generalizar os resultados aqui apresentados. Estudos futuros podem contribuir cobrindo um número maior de países, dedicando-se a examinar os efeitos de configurações institucionais específicas sobre a capacidade de definição de agenda dos parlamentares da oposição e da mídia. 


\section{REFERÊNCIAS}

André, A., Depauw, S., \& Martin, S. (2016). “Trust Is Good, Control Is Better": Multiparty Government and Legislative Organization. Political Research Quarterly, 69(1), 108-120. Recuperado de https:// doi.org/10.1177/1065912915623639

Bailer, S. (2011). People's Voice or Information Pool? The Role of, and Reasons for, Parliamentary Questions in the Swiss Parliament. The Journal of Legislative Studies, 17(3), 302-314. Recuperado de https://doi.org/10.1080/13572334.2011.595123

Bartels, L. M. (1996). Politicians and the Press: Who Leads, Who Follows? In Proceedings of the Annual Meeting of the American Political Science Association, San Francisco, USA.

Baumgartner, F. R., Breunig, C., \& Grossman, E. (2019). Comparative Policy Agendas: Theory, Tools, Data. Oxford, UK: Oxford University Press.

Baumgartner, F. R., \& Jones, B. D. (1993). Agendas and Instability in American Politics. Chicago, USA: University of Chicago Press.

Baumgartner, F. R., \& Jones, B. (2005). The politics of attention: How government prioritizes problems. Chicago, USA: University of Chicago Press.

Bevan, S., \& John, P. (2016). Policy Representation by Party Leaders and Followers: What Drives UK Prime Minister's Questions? Government and Opposition, 51(1), 59-83. Recuperado de https://doi.org/10.1017/ gov.2015.16

Beyme, K. von. (2000). Parliamentary Democracy. Democratization, destabilization, reconsolidation, 1789-1999. London, UK: Palgrave Macmillan.

Borghetto, E., \& Belchior, A. M. (2020). Party Manifestos, Opposition and Media as Determinants of the Cabinet Agenda. Political Studies, 68(1), 37-53. Recuperado de https://doi. org/10.1177/0032321718820738

Borghetto, E., \& Chaques-Bonafont, L. (2019). Parliamentary Questions. In F. R. Baumgartner, C. Breunig, \& E. Grossman (Eds.), Comparative Policy Agendas: Theory, Tools, Data (pp. 282-299). Oxford, UK: Oxford University Press.

Borghetto E., Santana-Pereira J., \& Freire, A. (2020). Parliamentary Questions as an Instrument for Geographic Representation: The Hard Case of
Portugal. Swiss Political Science Review, 26(1), 10-30. Recuperado de https://doi.org/10.1111/spsr.12387

Borghetto, E., \& Russo, F. (2018). From agenda setters to agenda takers? The determinants of party issue attention in times of crisis. Party Politics, 24(1), 65-77. Recuperado de https://doi. org/10.1177/1354068817740757

Boydstun, A. E. (2013). Making the News: Politics, the Media, and Agenda Setting. Chicago, USA: University of Chicago Press.

De Winter, L., \& Dumont, P. (2006). Do Belgian Parties Undermine the Democratic Chain of Delegation? West European Politics, 29(5), 957-976. Recuperado de https://doi.org/10.1080/01402380600968844

Deschouwer, K. (2012). The Politics of Belgium: Governing a Divided Society. London, UK: Palgrave Macmillan.

Edwards, G. C. E., \& Wood, B. D. (1999). Who Influences Whom? The President, Congress, and the Media. The American Political Science Review, 93(2), 32-344. Recuperado de https://doi. org/10.2307/2585399

Elgie, R., \& Grossman, E. (2016). Executive Politics in France: from leader to laggard? In R. Elgie, \& E. Grossman (Eds.), The Oxford Handbook of French Politics. Oxford, UK: Oxford University Press.

Eshbaugh-Soha, M., \& Peake, J. S. (2005). Presidents and the economic agenda. Political Research Quarterly, 58(1), 127-138.

Green-Pedersen, C. (2010). Bringing Parties into Parliament: The Development of Parliamentary Activities in Western Europe. Party Politics, 16(3), 347-369. Recuperado de https://doi. org/10.1177/1354068809341057

Green-Pedersen, C., \& Mortensen, P. B. (2010). Who sets the agenda and who responds to it in the Danish parliament? A new model of issue competition and agenda-setting. European Journal of Political Research, 49(2), 257-281.

Green-Pedersen, C., \& Walgrave, S. (2014). Agenda Setting, Policies, and Political Systems: A Comparative Approach. Chicago, USA: Chicago University Press.

Höhmann, D., \& Sieberer U. (2020). Parliamentary questions as a control mechanism in coalition governments. West European Politics, 43(1), 225-249. Recuperado de 10.1080/01402382.2019.1611986. 
Jensen, C. B., Proksch, S. O., \& Slapin, J. B. (2013). Parliamentary Questions, Oversight, and National Opposition Status in the European Parliament. Legislative Studies Quarterly, 38(2), 259-282. Recuperado de https://doi.org/10.1111/lsq.12013

Jones, B. D., \& Baumgartner, F. R. (2005). The Politics of Attention: How Government Prioritizes Problems. Chicago, USA: University of Chicago Press.

Jones, B. D., Larsen-Price, H., \& Wilkerson, J. (2009). Representation and American governing institutions. The Journal of Politics, 71(1), 277-290.

King, B. G., Bentele, K. G., \& Soule, S. A. (2007). Protest and Policymaking: Explaining Fluctuation in Congressional Attention to Rights Issues, 19601986. Social Forces, 86(1), 137-163. Recuperado de https://doi.org/10.1353/sof.2007.0101

Martin, L., \& Vanberg, G. (2011). Parliaments and Coalitions: The Role of Legislative Institutions in Multiparty Governance. Oxford, UK: Oxford University Press.

Martin, S. (2011). Using Parliamentary Questions to Measure Constituency Focus: An Application to the Irish Case. Political Studies, 59(2), 472-488. Recuperado de https://doi.org/10.1111/j.14679248.2011.00885.x

Navarro, J., \& Brouard, S. (2014). Who cares about the EU? French MPs and the Europeanisation of parliamentary questions. The Journal of Legislative Studies, 20(1), 93-108.

Norton, P. (1993). Does parliament matter? Coleshill, UK: Harvester Wheatsheaf.

Otjes, S., \& Louwerse, T. (2018). Parliamentary questions as strategic party tools. West European Politics, 41(2), 496-516. Recuperado de https://doi. org/10.1080/01402382.2017.1358936

Russo, F. (2011). The Constituency as a Focus of Representation: Studying the Italian Case through the Analysis of Parliamentary Questions. The Journal of Legislative Studies, 17(3), 290-301. Recuperado de https://doi.org/10.1080/13572334.2011.595122

Russo, F., \& Wiberg, M. (2010). Parliamentary Questioning in 17 European Parliaments: Some Steps towards Comparison. The Journal of Legislative Studies, 16(2), 215-232. Recuperado de https://doi. org/10.1080/13572331003740115
Saalfeld, T. (2000). Members of parliament and governments in western Europe: Agency relations and problems of oversight. European Journal of Political Research, 37(3), 353-376. Recuperado de https://doi.org/10.1111/1475-6765.00517

Sciarini, P., Varone, F., Gava, R., Brouard, S., Navarro, J., Palau, A. M., \& Vliegenthart, R. (2019). The Europeanization of Parliamentary Attention in and out of the European Union. In F. R. Baumgartner, C. Breunig, \& E. Grossman (Eds.), Comparative Policy Agendas: Theory, Tools, Data. Oxford, UK: Oxford Scholarship Online.

Seeberg, H. B. (2016). Opposition Policy Influence through Agenda-setting: The Environment in Denmark, 1993-2009. Scandinavian Political Studies, 39(2), 185-206. Recuperado de https://doi. org/10.1111/1467-9477.12062

Sevenans, J. (2018). How mass media attract political elites' attention. European Journal of Political Research, 57(1), 153-170. Recuperado de https://doi. org/10.1111/1475-6765.12220

Sevenans, J., \& Vliegenthart, R. (2016). Political Agenda-Setting in Belgium and the Netherlands: The Moderating Role of Conflict Framing. Journalism \& Mass Communication Quarterly, 93(1), 187-203. Recuperado de https://doi. org/10.1177/1077699015607336

Soroka, S. N. (2002). Agenda-Setting Dynamics in Canada. Vancouver, Canada: University of British Columbia Press.

Thesen, G. (2014). Political Agenda Setting as Mediatized Politics? Media-Politics Interactions from a Party and Issue Competition Perspective. The International Journal of Press/Politics, 19(2), 181-201. Recuperado de https://doi. org/10.1177/1940161213515756

Tsebelis, G. (1995). Decision Making in Political Systems: Veto Players in Presidentialism, Parliamentarism, Multicameralism and Multipartyism. British Journal of Political Science, 25(3), 289-325. Recuperado de https://doi. org/10.1017/S0007123400007225

Van Noije, L., Kleinnijenhuis, J., \& Oegema, D. (2008). Loss of Parliamentary Control Due to Mediatization and Europeanization: A Longitudinal and CrossSectional Analysis of Agenda Building in the United 
Kingdom and the Netherlands. British Journal of Political Science, 38(3), 455-478. Recuperado de https://doi.org/10.1017/S0007123408000239

van Santen, R., Helfer, L., \& van Aelst, P. (2013). When Politics Becomes News: An Analysis of Parliamentary Questions and Press Coverage in Three West European Countries. Acta Politica, 50(1), 45-63. Recuperado de https://doi.org/10.1057/ ap.2013.33

Vliegenthart, R., \& Walgrave, S. (2011). Content Matters: The Dynamics of Parliamentary Questioning in Belgium and Denmark. Comparative Political Studies, 44(8), 1031-1059. Recuperado de https:// doi.org/10.1177/0010414011405168

Vliegenthart, R., Walgrave, S., Baumgartner, F. R., Bevan, S., Breunig, C., Brouard, S. ... \& Tresch, A. (2016). Do the Media Set the Parliamentary Agenda? A Comparative Study in Seven Countries.
European Journal of Political Research, 55(2), 283301. Recuperado de https://doi.org/10.1111/14756765.12134

Walgrave, S., \& Van Aelst, P. (2006). The Contingency of the Mass Media's Political Agenda Setting Power: Toward a Preliminary Theory. Journal of Communication, 56(1), 88-109. Recuperado de https://doi.org/10.1111/j.1460-2466.2006.00005.x

Walgrave, S., \& Vliegenthart, R. (2012). The Complex Agenda-Setting Power of Protest: Demonstrations, Media, Parliament, Government, and Legislation in Belgium, 1993-2000. Mobilization: An International Quarterly, 17(2), 129-156.

Wiberg, M. (1995). Parliamentary questioning: Control by communication? In H. Döring (Ed.), Parliaments and Majority Rule in Western Europe (pp. 179-222). New York, NY: St Martin’s Press.

\section{Enrico Borghetto}

https://orcid.org/0000-0001-8676-3583

Professor Assistente na University of Florence. E-mail: enrico.borghetto@unifi.it

\section{Julie Sevenans}

https://orcid.org/0000-0003-2416-3878

Pesquisadora de pós-doutorado financiada pelo FWO (Fonds Wetenschappelijk Onderzoek); Trabalha na unidade de pesquisa Media, Movements \& Politics (M2P) no Departamento de Ciência Política da University of Antwerp. E-mail: julie.sevenans@uantwerpen.be

\section{Emiliano Grossman}

https://orcid.org/0000-0002-5547-6028

Professor associado de política na Sciences Po/CEE em Paris. E-mail: emiliano.grossman@sciencespo.fr 
RAP | (A falta de) Poder de definição de agenda do parlamento sobre a agenda de decisões executivas: evidências da Bélgica, França e Portugal

\section{APÊNDICE}

\section{ANEXO A MÉDIA DA ATENÇÃO SEMANAL AOS TÓPICOS, POR TÓPICO NAS PERGUNTAS PARLAMENTARES E NA AGENDA DO EXECUTIVO}

\section{Portugal}

\begin{tabular}{|c|c|c|c|c|}
\hline Tópico & Governistas PP & Oposição PP & Executivo & Mídia \\
\hline Macroeconomia & 34.74 & 26.72 & 4.36 & 8.76 \\
\hline Direitos e Liberdades & 0.00 & 0.65 & 1.34 & 3.62 \\
\hline Saude & 5.26 & 4.31 & 5.70 & 8.13 \\
\hline Agricultura & 0.00 & 1.72 & 7.38 & 1.36 \\
\hline Trabalho e emprego & 7.37 & 10.78 & 6.38 & 3.57 \\
\hline Educacao & 2.11 & 3.66 & 3.69 & 5.98 \\
\hline Ambiente & 0.00 & 0.00 & 3.36 & 1.26 \\
\hline Energia & 4.21 & 2.80 & 2.35 & 1.89 \\
\hline Migracoes & 0.00 & 0.22 & 0.34 & 0.84 \\
\hline Transportes & 3.16 & 5.17 & 7.72 & 4.25 \\
\hline Justica e Direito & 1.05 & 3.23 & 8.39 & 9.07 \\
\hline Politicas Sociais & 6.32 & 5.60 & 1.17 & 1.47 \\
\hline Habitacao & 0.00 & 2.16 & 2.68 & 1.21 \\
\hline Industria e comercio & 3.16 & 9.05 & 8.72 & 10.96 \\
\hline Defesa & 1.05 & 1.51 & 3.52 & 3.15 \\
\hline Ciencia & 2.11 & 0.43 & 2.68 & 2.94 \\
\hline Comercio externo & 7.37 & 1.51 & 1.85 & 0.94 \\
\hline Politica externa & 8.42 & 2.80 & 5.70 & 9.23 \\
\hline Governo & 13.68 & 17.67 & 14.09 & 16.83 \\
\hline Recursos naturais & 0.00 & 0.00 & 6.88 & 0.84 \\
\hline Cultura & 0.00 & 0.00 & 1.68 & 3.72 \\
\hline
\end{tabular}

Fonte: Elaborado pelos autores. 
RAP | (A falta de) Poder de definição de agenda do parlamento sobre a agenda de decisões executivas: evidências da Bélgica, França e Portugal

\section{Bélgica}

\begin{tabular}{lcccc}
\hline Tópico & Governistas PP & Oposição PP & Executivo & Mídia \\
\hline Macroeconomia & 6.71 & 7.43 & 4.77 & 5.02 \\
\hline Direitos e Liberdades & 3.17 & 2.96 & 2.78 & 4.39 \\
Saude & 11.99 & 7.77 & 6.97 & 5.97 \\
Agricultura & 1.89 & 2.01 & 2.73 & 1.91 \\
Trabalho e emprego & 8.07 & 6.48 & 7.48 & 5.54 \\
Ambiente & 2.64 & 2.57 & 2.44 & 1.93 \\
Energia & 2.19 & 2.74 & 2.82 & 1.73 \\
Migracoes & 4.98 & 6.76 & 1.61 & 2.71 \\
Transportes & 12.29 & 9.45 & 3.50 & 3.93 \\
Justica e Direito & 14.40 & 16.15 & 8.56 & 14.21 \\
Politicas Sociais & 4.45 & 4.47 & 4.36 & 1.96 \\
Industria e comercio & 6.41 & 4.64 & 4.87 & 10.34 \\
Defesa & 3.24 & 3.41 & 4.39 & 6.52 \\
Ciencia & 2.64 & 1.84 & 2.88 & 1.81 \\
Comercio externo & 0.98 & 1.12 & 1.31 & 0.78 \\
Politica externa & 6.11 & 6.93 & 10.81 & 9.69 \\
Governo & 7.84 & 13.25 & 27.72 & 21.56 \\
\hline
\end{tabular}

Fonte: Elaborado pelos autores.

\section{França}

\begin{tabular}{lcccc}
\hline Tópico & Governistas PP & Oposição PP & Executivo & Mídia \\
\hline Macroeconomia & 7.38 & 7.24 & 4.56 & 8.95 \\
\hline Direitos e Liberdades & 0.44 & 1.17 & 2.28 & 3.08 \\
Saude & 12.26 & 13.43 & 4.56 & 1.11 \\
Agricultura & 6.42 & 4.91 & 1.93 & 5.82 \\
Trabalho e emprego & 3.96 & 3.68 & 8.25 & 2.19 \\
Educacao & 6.93 & 7.13 & 5.09 & 1.78 \\
\hline Ambiente & 5.09 & 4.73 & 4.04 &
\end{tabular}


RAP | (A falta de) Poder de definição de agenda do parlamento sobre a agenda de decisões executivas: evidências da Bélgica, França e Portugal

\begin{tabular}{|c|c|c|c|c|}
\hline Tópico & Governistas PP & Oposição PP & Executivo & Mídia \\
\hline Energia & 1.23 & 2.04 & 2.28 & 0.66 \\
\hline Migracoes & 0.82 & 0.88 & 1.58 & 0.87 \\
\hline Transportes & 12.91 & 12.38 & 5.44 & 1.21 \\
\hline Justica e Direito & 6.39 & 6.78 & 8.60 & 6.22 \\
\hline Politicas Sociais & 4.78 & 4.44 & 2.28 & 0.78 \\
\hline Habitacao & 6.45 & 6.13 & 2.11 & 0.66 \\
\hline Industria e comercio & 3.45 & 2.92 & 10.35 & 4.32 \\
\hline Defesa & 2.46 & 2.63 & 3.33 & 8.43 \\
\hline Ciencia & 1.71 & 1.75 & 0.88 & 1.72 \\
\hline Comercio externo & 0.65 & 0.82 & 1.05 & 2.16 \\
\hline Politica externa & 1.71 & 1.81 & 12.46 & 9.64 \\
\hline Governo & 9.67 & 9.35 & 16.49 & 15.73 \\
\hline Recursos naturais & 2.60 & 3.74 & 0.18 & 0.06 \\
\hline Cultura & 2.70 & 2.04 & 2.28 & 16.59 \\
\hline
\end{tabular}

Fonte: Elaborado pelos autores.

ANEXO B DETERMINANTES DA ATENÇÃO DADA AOS TÓPICOS NA AGENDA DO EXECUTIVO COM T COMO DEFASAGEM DE TEMPO

\begin{tabular}{lccc} 
& $\begin{array}{c}\text { Modelo 1 } \\
\text { Efeitos principais }\end{array}$ & $\begin{array}{c}\text { Modelo 2 } \\
\text { Interação }\end{array}$ & $\begin{array}{c}\text { Modelo } 3 \\
\text { Interação }\end{array}$ \\
\hline Mídia(lag2) & 0.028 & 0.036 & 0.011 \\
& $(0.028)$ & $(0.029)$ & $(0.031)$ \\
Executivo(lag2) & $0.044^{* * *}$ & $0.045^{* * *}$ & $0.044^{* * *}$ \\
& $(0.012)$ & $(0.012)$ & $(0.012)$ \\
Governistas PP (lag2) & -0.001 & 0.008 & -0.001 \\
& $(0.013)$ & $(0.017)$ & $(0.013)$ \\
Oposição PP (lag2) & -0.009 & -0.009 & -0.025 \\
& $(0.015)$ & $(0.015)$ & $(0.021)$ \\
França & $0.006^{*}$ & $0.006^{*}$ & $0.007^{*}$ \\
\end{tabular}


RAP | (A falta de) Poder de definição de agenda do parlamento sobre a agenda de decisões executivas: evidências da Bélgica, França e Portugal

\begin{tabular}{|c|c|c|c|}
\hline & $\begin{array}{c}\text { Modelo } 1 \\
\text { Efeitos principais }\end{array}$ & $\begin{array}{l}\text { Modelo } 2 \\
\text { Interação }\end{array}$ & $\begin{array}{l}\text { Modelo } 3 \\
\text { Interação }\end{array}$ \\
\hline Portugal & $\begin{array}{c}0.006 \\
(0.005)\end{array}$ & $\begin{array}{l}0.006 \\
(0.005)\end{array}$ & $\begin{array}{l}0.006 \\
(0.005)\end{array}$ \\
\hline Mídia(lag2)*Governistas & & -0.126 & \\
\hline PP(lag2) & & (0.152) & \\
\hline Mídia(lag2)*0posição & & & 0.210 \\
\hline PP(lag2) & & & $(0.172)$ \\
\hline Observações & 8685 & 8685 & 8685 \\
\hline
\end{tabular}

Nota: Coeficientes dos efeitos fixos do tópico principal não apresentados na tabela. $\mathrm{p}<0,05 \quad{ }^{* *} \mathrm{p}<0,01 \quad{ }^{* * *} \mathrm{p}<0,001$ Fonte: Elaborado pelos autores.

\begin{tabular}{|c|c|c|c|c|c|c|c|c|c|}
\hline & BE & FR & PT & $\mathrm{BE}$ & FR & PT & BE & FR & PT \\
\hline Mídia(lag2) & $\begin{array}{c}0.010 \\
(0.023)\end{array}$ & $\begin{array}{l}-0.048 \\
(0.052)\end{array}$ & $\begin{array}{c}0.082 \\
(0.062)\end{array}$ & $\begin{array}{l}0.011 \\
(0.024)\end{array}$ & $\begin{array}{l}-0.033 \\
(0.055)\end{array}$ & $\begin{array}{c}0.094 \\
(0.063)\end{array}$ & $\begin{array}{l}-0.012 \\
(0.026)\end{array}$ & $\begin{array}{l}-0.022 \\
(0.055)\end{array}$ & $\begin{array}{c}0.049 \\
(0.071)\end{array}$ \\
\hline Executivo(lag2) & $\begin{array}{c}0.002 \\
(0.016)\end{array}$ & $\begin{array}{c}0.018 \\
(0.015)\end{array}$ & $\begin{array}{c}0.026 \\
(0.032)\end{array}$ & $\begin{array}{c}0.002 \\
(0.016)\end{array}$ & $\begin{array}{c}0.018 \\
(0.015)\end{array}$ & $\begin{array}{l}0.031 \\
(0.032)\end{array}$ & $\begin{array}{c}0.003 \\
(0.016)\end{array}$ & $\begin{array}{c}0.019 \\
(0.015)\end{array}$ & $\begin{array}{c}0.025 \\
(0.032)\end{array}$ \\
\hline Governistas PP (lag2) & $\begin{array}{c}0.005 \\
(0.010)\end{array}$ & $\begin{array}{l}-0.048 \\
(0.034)\end{array}$ & $\begin{array}{l}0.045^{*} \\
(0.015)\end{array}$ & $\begin{array}{c}0.007 \\
(0.014)\end{array}$ & $\begin{array}{l}-0.029 \\
(0.041)\end{array}$ & $\begin{array}{l}0.058^{*} \\
(0.021)\end{array}$ & $\begin{array}{c}0.006 \\
(0.010)\end{array}$ & $\begin{array}{l}-0.043 \\
(0.034)\end{array}$ & $\begin{array}{l}0.045^{*} \\
(0.015)\end{array}$ \\
\hline Oposição PP(lag2) & $\begin{array}{l}-0.006 \\
(0.012)\end{array}$ & $\begin{array}{l}-0.012 \\
(0.028)\end{array}$ & $\begin{array}{l}-0.010 \\
(0.032)\end{array}$ & $\begin{array}{l}-0.006 \\
(0.012)\end{array}$ & $\begin{array}{l}-0.010 \\
(0.029)\end{array}$ & $\begin{array}{l}-0.009 \\
(0.032)\end{array}$ & $\begin{array}{l}-0.026 \\
(0.017)\end{array}$ & $\begin{array}{c}0.022 \\
(0.036)\end{array}$ & $\begin{array}{l}-0.041 \\
(0.046)\end{array}$ \\
\hline $\begin{array}{l}\text { Mídia(lag2) }{ }^{\star} \text { Governistas } \\
\text { PP(lag2) }\end{array}$ & & & & $\begin{array}{l}-0.022 \\
(0.106)\end{array}$ & $\begin{array}{l}-0.290 \\
(0.371)\end{array}$ & $\begin{array}{l}-0.199 \\
(0.221)\end{array}$ & & & \\
\hline $\begin{array}{l}\text { Mídia(lag2)*Oposição } \\
\text { PP(lag2) }\end{array}$ & & & & & & & $\begin{array}{c}0.215 \\
(0.121)\end{array}$ & $\begin{array}{l}-0.600 \\
(0.384)\end{array}$ & $\begin{array}{c}0.348 \\
(0.375)\end{array}$ \\
\hline Observações & 3519 & 4158 & 1008 & 3519 & 4158 & 1008 & 3519 & 4158 & 1008 \\
\hline
\end{tabular}

Nota: Coeficientes dos efeitos fixos do tópico principal não apresentados na tabela. $\mathrm{p}<0,05 \quad{ }^{* *} \mathrm{p}<0,01 \quad{ }^{* * *} \mathrm{p}<0,001$ Fonte: Elaborado pelos autores. 
RAP | (A falta de) Poder de definição de agenda do parlamento sobre a agenda de decisões executivas: evidências da Bélgica, França e Portugal

ANNEX C DETERMINANTES DA ATENÇÃO DADA AOS TÓPICOS NA AGENDA DO EXECUTIVO COM T COMO DEFASAGEM DE TEMPO

\begin{tabular}{|c|c|c|c|}
\hline & $\begin{array}{c}\text { Modelo } 1 \\
\text { Efeitos principais }\end{array}$ & $\begin{array}{l}\text { Modelo } 2 \\
\text { Interação }\end{array}$ & $\begin{array}{l}\text { Modelo } 3 \\
\text { Interação }\end{array}$ \\
\hline Mídia(lag3) & $\begin{array}{c}0.049 \\
(0.029)\end{array}$ & $\begin{array}{c}0.051 \\
(0.031)\end{array}$ & $\begin{array}{l}0.016 \\
(0.032)\end{array}$ \\
\hline Executivo(lag3) & $\begin{array}{l}0.0266^{*} \\
(0.012)\end{array}$ & $\begin{array}{l}0.0266^{*} \\
(0.012)\end{array}$ & $\begin{array}{l}0.025^{*} \\
(0.012)\end{array}$ \\
\hline Governistas PP(lag3) & $\begin{array}{l}-0.024 \\
(0.014)\end{array}$ & $\begin{array}{l}-0.021 \\
(0.018)\end{array}$ & $\begin{array}{l}-0.024 \\
(0.014)\end{array}$ \\
\hline Oposição PP(lag3) & $\begin{array}{c}0.018 \\
(0.016)\end{array}$ & $\begin{array}{l}0.018 \\
(0.016)\end{array}$ & $\begin{array}{l}-0.017 \\
(0.022)\end{array}$ \\
\hline França & $\begin{array}{l}0.007^{*} \\
(0.003)\end{array}$ & $\begin{array}{l}0.007^{*} \\
(0.003)\end{array}$ & $\begin{array}{l}0.007^{*} \\
(0.003)\end{array}$ \\
\hline Portugal & $\begin{array}{l}0.007 \\
(0.005)\end{array}$ & $\begin{array}{l}0.007 \\
(0.005)\end{array}$ & $\begin{array}{l}0.006 \\
(0.005)\end{array}$ \\
\hline $\begin{array}{l}\text { Mídia(lag3)*Governistas } \\
\text { PP(lag3) }\end{array}$ & & $\begin{array}{l}-0.038 \\
(0.155)\end{array}$ & \\
\hline $\begin{array}{l}\text { Mídia(lag3)*Oposição } \\
\text { PP(lag3) }\end{array}$ & & & $\begin{array}{l}0.427^{*} \\
(0.177)\end{array}$ \\
\hline Observações & 8129 & 8129 & 8129 \\
\hline
\end{tabular}

Nota: Coeficientes dos efeitos fixos do tópico principal não apresentados na tabela. $\mathrm{p}<0,05 \quad{ }^{* *} \mathrm{p}<0,01 \quad{ }^{* * *} \mathrm{p}<0,001$ Fonte: Elaborado pelos autores.

\begin{tabular}{lcccccccccc} 
& BE & FR & PT & BE & FR & PT & BE & FR & PT \\
\hline Mídia(lag3) & 0.017 & 0.018 & -0.003 & 0.016 & 0.024 & 0.008 & -0.010 & -0.005 & -0.018 \\
& $(0.023)$ & $(0.054)$ & $(0.068)$ & $(0.025)$ & $(0.058)$ & $(0.069)$ & $(0.026)$ & $(0.057)$ & $(0.078)$ \\
Executivo(lag3) & 0.020 & -0.007 & 0.040 & 0.020 & -0.006 & 0.044 & 0.021 & -0.007 & 0.039 \\
& $(0.017)$ & $(0.016)$ & $(0.035)$ & $(0.017)$ & $(0.016)$ & $(0.035)$ & $(0.017)$ & $(0.016)$ & $(0.035)$ \\
Governistas PP(lag3) & 0.015 & -0.084 & -0.012 & 0.014 & -0.076 & -0.001 & 0.017 & $-0.089 *$ & -0.012 \\
& $(0.011)$ & $(0.035)$ & $(0.016)$ & $(0.014)$ & $(0.043)$ & $(0.023)$ & $(0.011)$ & $(0.035)$ & $(0.016)$ \\
Oposição PP(lag3) & 0.006 & 0.036 & -0.001 & 0.006 & 0.037 & -0.000 & -0.021 & 0.005 & -0.016 \\
& $(0.012)$ & $(0.030)$ & $(0.034)$ & $(0.012)$ & $(0.030)$ & $(0.034)$ & $(0.017)$ & $(0.038)$ & $(0.049)$ \\
Mídia(lag3) ${ }^{*}$ Governistas & & & & 0.015 & -0.128 & -0.159 & & & \\
PP(lag3) & & & & $(0.109)$ & $(0.379)$ & $(0.230)$ & & & \\
Mídia(lag3) ${ }^{*}$ Oposiçãa & & & & & & & 0.277 & 0.537 & 0.159 \\
PP(lag3) & & & & & & & $(0.123)$ & $(0.402)$ & $(0.398)$ \\
Observações & 3383 & 3864 & 882 & 3383 & 3864 & 882 & 3383 & 3864 & 882 \\
\hline
\end{tabular}

Nota: Coeficientes dos efeitos fixos do tópico principal não apresentados na tabela. $\mathrm{p}<0,05^{* \star} \mathrm{p}<0,01 \quad{ }^{* * *} \mathrm{p}<0,001$ Fonte: Elaborado pelos autores. 